\title{
Research on the Trans-Boundary Ecological Strategic Transformation Model of Enterprises: XR \& DR Double Case
}

\author{
Li He*, Ouyang Taohua, Wenyan Song \\ School of Economics and Management, Beihang University, Beijing, 100191
}

Keywords: Border Crossing, Ecological Strategy, New Energy Enterprise

\begin{abstract}
With the continuous development of new technologies represented by the Internet, the traditional business rules are constantly being overturned. How to promote the development of new industries through enterprise strategy has become an important topic widely discussed. As the world's second largest economy, the government has issued multiple documents to promote the development of new energy industry. The enterprises represented by new energy and new information technology are leading a new upsurge of new industry development. Therefore, taking the new energy industry enterprises in China as the object of study, this paper explores the transformation mechanism of enterprise ecological strategy from the perspective of cross border with exploratory case study. Through the realization and transformation of the ecological strategy of the enterprise, the dependence of the customers is cultivated and the commercial ecology is realized.
\end{abstract}

\section{Introduction}

Entering the Internet era, cross-border and ecological enterprises have become an important feature of the enterprise. Traditional enterprises try to form new industrial ecology by crossing different industries and use new technology to reconstruct the competition pattern. In the enterprise market, each wave of technology update will bring the blowout of the solution demand. The enterprise solution provider, which can help the customers get through the technological tide and seize the technical bonus, has been on the top of the tide [1]. They are therefore trusted by the customers and are successful in locking up their customers. The theory of boundary crossing provides a suitable theoretical perspective for this article. In the Internet age, the biggest challenge for organizations is to provide excellent products and services to provide the user with a one-stop perfect experience. How the enterprise takes the user as the center, creates the new ecology, this urgently needs the enterprise to form the border crossing ability [2]. At the same time, the ability of border crossing also restricts the scope of its cross boundary.

In view of this, the purpose of this study is to take XR \& DR as the case study object, and to explore how the new energy enterprises achieve the strategy of border crossing in the Internet age. What are the motivations, paths and outcomes of these strategies? The specific research contents include the following three aspects: first, cross border and cross border recognition motivation of enterprises, second enterprises of the carrier; how to boundary spanning capabilities and strategic stage adaptation; third, the ability and strategy of adaptation to the enterprise the influence of cross boundary results.

\section{Literature Review and Research Framework}

Focusing on the research questions presented in this paper, this chapter reviews existing research results and related theories, grasps the existing research basis and context, and clarifies the theoretical inheritance relationship between this paper and existing research.

\subsection{Ecological strategy theory}

The essential problem of enterprise strategy is how to build a sustainable competitive advantage (SCAs). The ecological strategy is put forward based on the concept of ecology, it is because the 
enterprise strategic environment affects not only the dynamic change, and business strategy is also greatly affect the external environment, which requires the enterprise to have an overall understanding of the achievable competitive market as well as on the development and evolution of strategic groups have an overall grasp, in order to better identify market opportunities, the living space of mining enterprise strategy. This is essentially similar to the relationship between ecology and the study of the relationship between the organism and the environment in the ecosystem. Therefore, ecology provides a feasibility study for the strategic behavior of the enterprise and the environment. In the business ecosystem, the ecological strategy that the enterprises should take is divided into four categories: the cornerstone type, the dominant type, the gathering profit type and the slit type (see Table 1). Each type of strategy has different emphases.

Table 1 Classification of ecological strategies

\begin{tabular}{|c|c|c|c|c|}
\hline & Cornerstone & $\begin{array}{c}\text { Dominating } \\
\text { dominant type }\end{array}$ & $\begin{array}{c}\text { Take advantage } \\
\text { of it }\end{array}$ & Gap type \\
\hline Definition & $\begin{array}{l}\text { Actively improve the } \\
\text { overall health of the } \\
\text { ecosystem, benefit from } \\
\text { it, and make the } \\
\text { enterprise achieve a } \\
\text { sustainable competitive } \\
\text { advantage }\end{array}$ & $\begin{array}{c}\text { Vertical or } \\
\text { horizontal } \\
\text { integration to } \\
\text { occupy and control } \\
\text { most of the nodes } \\
\text { of the network }\end{array}$ & $\begin{array}{c}\text { Extracting as } \\
\text { much value as } \\
\text { possible from the } \\
\text { network, but not } \\
\text { directly } \\
\text { controlling the } \\
\text { network }\end{array}$ & $\begin{array}{c}\text { Having } \\
\text { professional } \\
\text { competence that } \\
\text { distinguishes } \\
\text { itself from other } \\
\text { network } \\
\text { members }\end{array}$ \\
\hline $\begin{array}{c}\text { Value } \\
\text { creation }\end{array}$ & $\begin{array}{l}\text { Leave most of the value } \\
\text { creation activities to the } \\
\text { network and share the } \\
\text { value of the internal } \\
\text { creation }\end{array}$ & $\begin{array}{l}\text { He is responsible } \\
\text { for most of the } \\
\text { value creation } \\
\text { activities }\end{array}$ & $\begin{array}{l}\text { Almost no value } \\
\text { creation, reliance } \\
\text { on network } \\
\text { members to } \\
\text { create value } \\
\end{array}$ & $\begin{array}{l}\text { This kind of } \\
\text { subject is } \\
\text { combined to } \\
\text { create most of } \\
\text { the value } \\
\end{array}$ \\
\hline $\begin{array}{l}\text { Strategic } \\
\text { focus }\end{array}$ & $\begin{array}{c}\text { Focus on creating a } \\
\text { platform and sharing } \\
\text { problem solutions in the } \\
\text { network }\end{array}$ & $\begin{array}{l}\text { Focus on control } \\
\text { and ownership }\end{array}$ & $\begin{array}{l}\text { In essence, it is a } \\
\text { strategy that does } \\
\text { not match action } \\
\text { and income. }\end{array}$ & $\begin{array}{c}\text { Focus on } \\
\text { subdivision of } \\
\text { the market, take } \\
\text { the way of } \\
\text { difference. }\end{array}$ \\
\hline
\end{tabular}

Data sources: Based on data consolidation

\subsection{Cross boundary theory}

"Boundary" contains two meanings: first, the boundary is based on some attribute difference to define the difference between things, that it will be the two systems from the qualitative aspects of distinction; second, the boundary is attribute to the external (internal) to expand the base, so the boundary and to link the two systems, the formation of osmosis system between [3]. It can be considered that the boundary itself is both static and dynamic. In other words, the boundary is a dominant or potential mechanism that makes the flow of two heterogeneous spaces normalized and simple, and makes it visible to [4]. The essence of the boundary is the boundary between the organization and the surrounding environment [5]. According to the organization's functions and activities, the organizational boundaries can be divided into four categories: the functional boundary, the level boundary, the boundary with customers, and the boundary with suppliers [6]. Therefore four types of boundary are proposed: vertical boundary, horizontal boundary, external boundary and geographical boundary. The so-called vertical boundaries, mainly reflected in the organizational hierarchy; between the horizontal boundary organization exists in different departments, different products or different project group; the exterior boundary is diaphragm organization and suppliers, customers, government agencies and community management of the external environment, the diaphragm is always quite distinct from each other in the traditional organization, makes it the other a relationship between some formed inside and outside the organization and the external environment; geographic boundaries generally exist in the complex structure of the transnational and trans regional organization in [7].

However, there are still gaps in research on the theory of boundary crossing. First, in recent years, research has focused on identifying and exploring the influencing factors of team cross-border 
cooperation: personal factors, environmental factors and organizational factors [8]. Although it is important to study the effect of cross border factors, but the lack of relationship between them or interaction analysis; secondly, in the research of enterprise organizational boundaries mainly focus on individual and organizational boundary spanning across the two aspects of strategy and its interaction analysis, the lack of suitable research on organizational boundary and cross border strategic coordination mechanism and path.

\subsection{Analytical framework}

Through the review of border crossing and the theory of ecological strategy, this paper studies the transformation process of enterprise's ecological strategy from the perspective of border crossing, and analyzes the framework, as shown in Figure 1.



Figure 1 An analytical framework

Source: the author collate

\section{Case Description}

\subsection{XR case description}

XR, founded in 2000, is a state-level high-tech enterprise engaged in R \& D, design, integration, engineering installation and maintenance of solar photovoltaic power generation system. Our products include solar off grid / micro grid ground power station, solar photovoltaic and building integrated system, solar off grid power supply, solar street lamp and solar water pump. These products are widely used in remote areas such as production and residential electricity, street lighting, communication base stations, automatic monitoring, traffic monitoring and forest fire prevention. The development process of XR can be divided into three stages:

\subsubsection{0-2007: solar photovoltaic off net power generation}

Aiming at the unique demand for off grid power generation, XR puts forward the combination technology, product and service integration solution (Integrated Solution) to meet users' needs. After undertaking a project, the company first dispatched the engineering designers to investigate the climatic and geographical conditions of the project and then design the overall implementation plan. The implementation plan includes control software, PV module, photovoltaic controller, inverter, battery, component bracket, hardware and software design, and arrange the whole system construction and installation. After the project was completed, the company began to purchase the equipment from the solar photovoltaic equipment manufacturers and commissioned the construction team to carry out the construction. The company is responsible for the field management and supervision in the construction. After the completion of the construction, the equipment is checked and debugged. Finally, the system is delivered to the project user. In this stage, the company has developed rapidly by virtue of excellent technology and good partnership.

\subsubsection{8-2010: entering the solar photovoltaic grid connected power market}

Before 2008, XR company was mainly engaged in off grid power generation business. For grid 
connected generation, it only stayed on the R \& D reserve level, and the actual commercialization operation didn't take place. Since 2000, foreign solar grid connected power generation has developed rapidly, and the United States and other developed countries have been popularized. However, with the attention of the state to the new energy, and the stimulation of the policy and the demonstration project, grid connected power generation ushered in a new development opportunity. $\mathrm{XR}$ also entered the market. In the grid connected power market, XR has built up the solar photovoltaic and building integration system, and has increased the content of the government demonstration project to assist customers. The project process is first to design the overall project for the customer, and then to declare the government project. After the declaration is successful, it enters the operation stage of the project, including facilities and equipment procurement, project construction and project inspection and commissioning. With the aid of national policy, a project can get $50 \%$ of the country's subsidy. But the income source still takes the net business as the main income, which accounts for $90 \%$ of the total income.

\subsubsection{1- today: power grid power generation market}

The company has conducted extensive research on how to develop the grid business and exchanges with domestic and foreign counterparts. After repeated discussions, a model of Energy Management Contracting, which is widely used in the field of foreign energy saving services, is widely used. Contract energy management pays the cost of energy saving projects by building energy saving projects by the investor and reducing the energy cost of the energy consuming units. After the completion of the contract, all the energy-saving equipment and the energy saving benefits it brings will be owned by the customers. This means that the XR company needs to complete the overall project design, investment, construction and operation, the customer does not need capital input, only need to provide space to install the grid power system, cost recovery and profit from electricity, customers do not have any financial pressure, but also get economic profit from energy saving projects. After the early demonstration, the scheme design and the joint negotiation final decision, the model is applied to the grid connected power generation market.

In the implementation of contract energy management, XR company also needs to have the ability to operate the whole project. XR companies need to cooperate with the certification and insurance companies to make the project meet the requirements for the implementation of the qualification. The company also needs to contact the Guarantee Corporation, various financial institutions and other enterprises to implement the funding source for the project.

\subsection{DR case description}

DR, founded in 2009, is a service company specializing in the field of new energy and electricity. The company business includes government advisory planning, investment and development of new energy projects, project implementation, network products and green industry finance, so far, the company has Huaneng, Datang, Huadian and other dozens of mainstream new energy development group more than 1000 project provides wind / photovoltaic power prediction products and services; to provide new energy grid scheduling products and services for the State Grid, China Southern Power Grid and etc.. At the same time, DR has worked with Chinese universities and scientific research institutes in the field of new energy application technology to obtain a number of patents and qualifications. The development process of DR is divided into three stages:

\subsubsection{9-2012 years: focus on products}

Since the establishment of DR in 2009, it coincides with the blue sea market in the early stage of the development of the wind power industry, with great market potential. At the beginning of a company, provides a new energy power generation forecasting based product system, dispatching management and support system, mainly for the five major power group, Naka Hiro, Huarun, SDIC electric power and dozens of mainstream new energy development group and State Grid, China Southern Power Grid, province, county and other more than 1000 projects provide product. The application of grid connected dispatching products can make up for the blank of Power Grid Corp's information management for distributed generation integration. It can mainly realize functions such 
as real-time monitoring of power generation, generation statistics analysis, dispatching assistant decision-making, geographic information display and so on.

With the increase of the grid capacity, some wind power bases are constantly taking off the wind turbine off the net. In the early days, the problem of wind power safety and transmission of wind power, which is generally worried by the industry, has become a real accident. Due to the widespread neglect of technology and management defects in the installation stage, fan trip accidents happen frequently, which has a serious impact on the safe operation of wind farms and power grids. At the same time, the wind power industry is also faced with the installation machine to worry about "grid", and after the grid and encountered the embarrassment of "abandoning the wind".

\subsubsection{2-2015 years: the upper and lower extension of the industrial chain}

Starting from the grid connected products the end product of the power grid can drive the sales of the power terminal products. Customers can become the customer group of operation and maintenance business. Channel reuse can promote operation and maintenance business, and the development of downstream operation and maintenance business is fully linked with core products. Then how should the upstream of the core product develop to produce a long tail effect? DR is located in the original consulting and planning business, consulting business as a traction business, which can provide the government with suggestions for energy structure adjustment and new energy demonstration city planning. The early accumulation of government relations can support the development of investment business, and the long tail of consultation is the investment business that drives the marketing and operation of the integrated products and operations. Until 2015, the company opened the project to develop the upstream and downstream industry chain. The consulting department provides development advice, fund company provides financial support, engineering construction company design and implementation. Technology companies provide centralized control system and predict new energy power generation and power grid control. Operation and maintenance company is responsible for operation and maintenance after completion of the project, and truly realizes group control and coordination.

\subsubsection{5- up to now: building the Internet platform}

As the power grid continues to digitize, the integration of the Internet in the energy system constitutes the energy Internet. The platform building of DR has three stages:

The first stage: the establishment of the "new energy gate" website. After accumulating a large amount of data and enterprise capabilities, DR takes the website as an entrance to build the energy Internet platform. The core advantage of DR is the data application plate, including the actual operating data of wind and photoelectric fields, such as meteorological data, geographic resource data, equipment detection data and so on. Such as meteorological data, it can be visualized and used to integrate data from domestic and international meteorological data and meteorological data of DR, so as to achieve investors' initial value assessment for new energy projects. The second stage: research and development of "cattle break" APP. As an e-commerce platform, "Niu Bang" can facilitate the transaction of equipment suppliers, investors, common agencies and third party operation and maintenance enterprises, move the equipment procurement links to online, and achieve interaction among participants through equipment reviews. However, because a lot of important parameters cannot be obtained due to the small amount of data and confidentiality, equipment procurement is still mostly offline bidding, and online reviews are mostly ignored. Therefore, "Niu Bang" needs further research and development. The third stage: the development of the "energy Cube" platform. The platform is based on the new energy policy to solve the government's energy intelligent management and control products. By using the data and linkage effects of new energy gate and Niu bang, we can cooperate with the government with existing cooperation and combine the local geographic information to meet the functions of the government resource planning. At the same time, arrange investment and consultation department personnel, visit the target town and survey the customer needs. 


\section{Case Analysis}

\subsection{Span boundary drivers}

\subsubsection{Take advantage of the opportunity}

The use of opportunity refers to the discovery of a new market opportunity, which is mostly the triggered by new technologies and new needs. In the case of XR, founders found that all kinds of field facilities and remote areas all need to use off grid power generation technology, so the company located in off grid power providers, integrated design and construction approach to enter the market. The state guides the development of photovoltaic grid connected technology, which has led to the rapid growth of the market. XR company quickly perceives this market opportunity and enters the market in a timely manner. However, because the government's support is an important factor to promote the development of the market, many enterprises willing to launch photovoltaic grid connected power generation projects are supported by state funds. If we fully follow the integrated design and construction mode, we will lose a large number of customers, so XR company has changed the original mode in order to grasp this new market opportunity, and has increased the service to declare the government project [9].

In the case of DR company, the competition of grid products is becoming more and more fierce, the profit space is gradually shrinking, and the company decides to start the transformation. The state's strong support for the new energy policy has also promoted the process of the transformation of the company. DR began to extend diversified products and services from a single product, extending from power generation business to upstream investment development terminal and downstream operation and maintenance terminal of industrial ecological chain. Through transformation, DR has not only grasped the new opportunities in the new energy market, but also expanded its business scope to the whole industry chain, expanding the participation in the new energy market.

\subsubsection{Exploring opportunities}

Exploring opportunities is a further excavation of market opportunities and a further expansion of the new business [10]. In the photovoltaic grid generation market, DR has changed the construction mode of integrated design. But this mode didn't get the expected market share, and even a number of contracted customers canceled the project. The reason is that the funds pressure faced by customers is too large. Customers invest huge funds to build photovoltaic grid connected power generation projects. The annual cost of electricity consumption is limited, and the recovery of investment will take more than ten years. The economic benefits of input and output will not be attractive to customers. Therefore, DR adopts the contract energy management mode, and the company invested in building power generation projects to solve the financial obstacles that customers worry about, and successfully introduce photovoltaic grid connected power generation projects into the market.

After DR extends the upstream and downstream industry chain, in order to make full use of its data resources accumulated in traditional business areas, the company began to strengthen the online platform construction, and gradually develop from the traditional offline business mode to the Internet sharing platform. First of all, we start with website and take publicity as an entry to achieve data integration and mining. At the same time, we can also achieve the value evaluation of new energy projects for investors. The implementation of "new energy gate", "Niu Bang" and "energy Cube" have positioned DR in the Internet big data service company, specializing in technology products and big data business, and lay a good foundation for the development of energy Internet in the future.

\subsection{Cross boundary carrier}

In the case of XR company, although XR's initial concept of solar power generation is approved by customers, the cost of PV module and installation is relatively high. Choosing grid connected power generation products needs to invest more funds at once, so sales volume is not optimistic. In 
the introduction of the contract energy management system, taking XR company by the construction side into the investment side, from the power generation system is provided to the user into electric energy, the source of income is engineering income into user charge income from the enterprise and the customer each one takes what he needs to achieve mutual benefit. Taking the contract energy management as the carrier of the border crossing, XR company has realized a benign ecological cycle to create value with the customer.

In the case of DR, the enterprise embarks from the product, carries on two strategic transformation, extends from the product to the whole industry chain, and extends from the industrial chain to the whole platform. The essence of the transformation is the integration of advantages, natural resources and the transition from offline to the line. Using the Internet, APP, create new energy, energy, cattle breaking three cube online products, digital platform as a carrier across the border, increase the drainage, not only full activation of data resources, but also the integration of external resources, customers, suppliers, enterprises all inclusive ecological circle in enterprise.

\subsection{Trans-boundary strategic transformation}

\subsubsection{Vertical complementary boundary strategy}

Vertical complementarity refers to controlling different links of an experiential chain, starting from a single point of strength, and constantly replenishing resources for every link in the chain, so as to create a complementary [11]. When two products or services are used together, the value is greater than the sum of value they are used separately, which is the complementary [12]. These complementary products can exist between software and hardware, and between different applications. This means that it is necessary to upgrade the existing product threshold into a threshold of a complementary system, starting with some of the core competencies that are already available. By complementing the product and service, it can help the enterprise to use, maintain the product and transform the business process to perfect the product. The most obvious advantage of vertical complementarity strategy is high input and sales volume. In a closed loop, the investment of a link will drive all other links to the greatest extent, and then turn into the whole chain profit.

XR has changed from the original system provider to power generation to energy - providing energy providers to solve the electricity problem for users. During this process, the company added new service activities in the original mode, including adding new business activities, extending business process and changing business operation mode. Such as engineering design and demonstration project declaration, and then the construction of the project, solved the problem of power consumption, at the same time, it is consistent with the national policy requirements for the development of new energy. Looking at the development process of DR, it is a process of continuous interaction between the vertical complementarity of the product as the core. Starting from the grid products, the enterprise extends the consultation to the upstream, the downstream expansion and operation, the upper and the middle and lower linkage complementation system. The binding of this complementary product and service can improve the perceived value and the threshold of competition, and establish a long-term relationship with the user. Under the condition that the market position is not strong enough and the resources are relatively tight, the longitudinal complementary strategy is preferable.

\subsubsection{Horizontal complementary boundary strategy}

Lateral complementary means around a link increasing to a large piece, driven by many boy, look forward to future collaboration between the formation of pawn, user nets, which means that each link which are the complementary combination of an important part, maintain customer interaction, increase the transfer cost of [13]. Horizontal complementarity is a scalable network that supports more demand scenarios. By adopting cross complementarity strategy, we can get more diverse user data and get a more comprehensive cognition of [14]. A horizontal complementary unit can be a product or a platform.

In the case of XR, the strategy of horizontal complementarity makes the economic entities 
connected with XR company expand from equipment suppliers, project construction units and customers to partners such as insurance companies, financial institutions and testing and certification institutions. XR company, according to the process of the project adjustment and the need to cooperate with these enterprises, to obtain the necessary resources, certification, production, construction and other aspects.

In the case of DR, the company established a new energy Internet platform, with all kinds of hardware manufacturers, software developers are more developed in close cooperation, in the implementation process, in order to enrich the project resources as a starting point, through subsidies distributed resource owners, so that large amounts of distributed resources in the platform, cited in the project investors. Through platform, we can realize the investment and development of distributed projects, and stimulate more resources owners and share resources. Investors who will benefit from this platform will do more investment based on this platform, as well as related projects, such as bidding, equipment purchase, etc. In this platform, there are government, individuals, suppliers and other upstream and downstream organizations. Different organizations are also active on one platform, providing consultation advice by the consulting department. The fund company provides financial support, the design and implementation of the engineering construction company, and the technology company provides a centralized control system to predict the power generation and power of new energy. DR has become a platform enterprise that provides a variety of energy service functions from the industrial chain.

\section{Research Contribution and Prospect}

\subsection{Research summary}

Through the induction and analysis of the above case enterprises, the dynamic transformation model of enterprise's ecological strategy is formed, and the transformation motivation causes the transformation of enterprise's ecological strategy. In the development process of new energy enterprises, grasping market opportunities is the main cause of transformation, which is manifested in expanding opportunities to related business areas and exploring opportunities to infiltrate existing business areas. Different conversion drivers will lead to changes in business thinking and make different decisions.

Through the case analysis can be found, the conversion of the ecological strategy is divided into internal and external ecological strategy of ecological strategy, internal / external ecological strategic relationship can be staged, such as after the first period, or after the first addition; can also be a complementary relationship, promote ecological formation, in to promote the ecological rigor, they formed the value proposition of the ecological strategy.

\subsection{Research contribution}

The theoretical contribution of this article is reflected in two aspects:

First, the "black box" of the transformation of ecological strategy has been opened, and the ecological strategy theory of the development of international management along the front of the school is supplemented and developed. The research on Ecological Strategy in academic circles is scattered and no specific definition. However, with the rapid development of Internet and big data in China, the theoretical guidance of ecological strategy has been weak. This research extends and supplements on the basis of existing theories, reveals the transformation of enterprise's ecological strategy from the perspective of cross boundary, and enriches the theoretical system of ecosystem.

Second, a comprehensive discussion of the boundary leapfrog promotes the reform and innovation of the enterprises. According to the traditional research from the perspective of the blind spot, this study introduces boundary crossing angle, through the implementation of the strategy of ecological situation, to fill the gap, the ecological strategy and its ability, as well as the interaction between each other, there is a new understanding, and challenge to help change the academic understanding of the enterprise innovation better.

Practical significance, this research conclusion has important guiding significance for Chinese 
enterprises in the Internet environment, how to build ecological strategy through different paths to form sustainable development competitive advantage. The path of building an ecological strategy based on a cross boundary perspective is of far-reaching practical significance for Chinese enterprises to choose the differentiated business model.

\section{Acknowledgements}

The authors would like to thank the National Natural Science Foundation of China (71632002, 71172176, 71472012, 71529001).

\section{References}

[1] Aldrich H, Herker D. Boundary Spanning roles and Organization Structure [J]. Academy of Management Review, 1977, 2(2):217-230.

[2] Bettencourt L A, Brown S W. Role stressors and customer-oriented boundary-spanning behaviors in service organizations [J]. Journal of the Academy of Marketing Science, 2003, 31(4):394-408.

[3] Curnin S, Owen C, Trist C. Managing the constraints of boundary spanning in emergency management [J]. Cognition Technology \& Work, 2014, 16(4):549-563.

[4] Dollinger M J. “Environmental Boundary Spanning and Information Processing Effects on Organizational Performance [J]. Academy of Management Journal, 1984, 27(2):351-368.

[5] D. G. Ancona, “Outward bound: Strategies for team survival in an organization,” Acad. Manage. J., vol. 32, no. 2, pp. 334-365, 1990.

[6] Wenyu Du; Shan Ling Pan, "Boundary spanning by design: Toward aligning boundary spanning capability and strategy in IT outsourcing,” IEEE Transactions on Engineering Management, vol.60, no.1, pp. 59-76.2013.

[7] Edelenbos J, Meerkerk I V. Connective capacity in water governance practices: The meaning of trust and boundary spanning for integrated performance [J]. Current Opinion in Environmental Sustainability, 2015, 12:25-29.

[8] Faraj S,Yan A. Boundary work in knowledge teams[J].Journal of Applied Psychology, 2009,4 (3): 604-617.

[9] Fleming L, Waguespack D M. Brokerage, Boundary Spanning, and Leadership in Open Innovation Communities [J]. Organization Science, 2007, 18(2):165-180.

[10] Gulati R. Tent poles, tribalism, and boundary spanning: The rigor-relevance debate in management research [J]. Academy of Management Journal, 2007, 50(4):775-782.

[11] Levina, Natalia, Vaast, Emmanuelle. The emergence of boundary spanning competence in practice: implications for implementation and use of information systems [J]. Mis Quarterly, 2005, 29(2):335-363.

[12] Marrone, Jennifer A, Tesluk, et al. A Multilevel Investigation of Antecedents and Consequences of Team Member Boundary-Spanning Behavior [J]. Academy of Management Journal, 2007, 50(6):1423-1439.

[13] M. L. Tushman and T. J. Scanlan, "Characteristics and external orientations of boundary spanning individuals,” Acad. Manage. J., vol. 24, no. 1, pp. 83-98, 1981

[14] Rosenkopf L, Nerkar A. Beyond local search: boundary-spanning, exploration, and impact in the optical disk industry [J]. Strategic Management Journal, 2001, 22(4):287-306. 